\title{
APRESENTAÇÃO: ETNOGRAFIAS SOCIOLÓGICAS DE UM MUNDO DO TRABALHO RECONFIGURADO
}

\author{
Pedro Robertt ${ }^{\prime}$
}

Pedro Lisdero ${ }^{2}$

Elizardo Scarpati Costa ${ }^{3}$

Revitalizar os estudos etnográficos, desde um olhar sociológico, parece um contrassenso histórico. Em uma época em que a palavra globalização tem invadido as diversas áreas de conhecimento parece, no mínimo, improcedente ir atrás de alternativas conceituais e de pesquisa que, à primeira vista, parecem situar-se nos níveis "micro" da análise científico-social.

A essa primeira provocação investigativa e cognitiva precisa ser acrescentado que as transformações no mundo do trabalho hoje aumentam os desafios teóricos, metodológicos e epistemológicos do fazer sociológico, levando à necessidade de uma busca por formas inovadoras de abordagens.

Ao lançar este dossiê de artigos, que são frutos de pesquisas etnográficas sociológicas (dentro do contexto geral das ciências sociais), na área do trabalho, estamos justamente resgatando uma abordagem que não é tão nova, mas que hoje parece muito promissora para enfrentar os desafios colocados.

Certamente, não estamos sozinhos neste argumento. De fato, autores como o sociólogo britânico Michael Burawoy (que contribuiu para este dossiê), mas não unicamente, têm reivindicado a pertinência e as potencialidades dos estudos etnográficos em uma época de

\footnotetext{
1 Professor Adjunto da Universidade Federal de Pelotas, atuando no Programa de Pós-graduação em Sociologia (PPGS) e no Programa de Pós-graduação em Ciência Política (PPGCPol). E-mail: probertt21@gmail.com.

2 Professor da Universidad Nacional de Villa María, Co-director del "Programa de Estudios sobre Acción Colectiva y Conflicto Social" (CIECS - CONICET y UNC), Director de Estudios Sociológicos Editora (ESEditora - CIES)). E-mail: pedrolisdero@gmail.com.

3 Professor Adjunto de Sociologia do Instituto de Ciências Humanas e da Informação (ICHI) e do Mestrado em Direito e Justiça Social (PPGD) da Universidade Federal de Rio Grande (FURG). Email: eliscarpati@hotmail.com.
} 
globalização, informacionalização e fluxos de capitais e de trabalhadores em escala planetária (Burawoy, 1991; Burawoy, 2000).

Talvez, porque muitas vezes se tem associado - erradamente - a etnografia com uma visão singularmente míope da sociedade é que se tem achado, que essa abordagem não poderia nos dizer nada de novo para além do que está diante de nossos narizes. Os organizadores deste número temático entendem, que mais do que nunca, precisamos de perspectivas inovadoras que nos levem para os microfundamentos da sociedade em geral e das relações de trabalho em particular, e que isso não significa abdicar de análises e interpretações mais generalizadoras da vida social. Pari Passu, argumentamos que não há um hiato intransponivel nos estudos das realidades cotidianas a que se veem enfrentados os trabalhadores e as grandes forças locais, regionais, estatais ou mundiais. Estas forças nunca foram na realidade uma variável externa ou de contexto, sempre existiram imbricadas no cotidiano, palpitantes na realidade local, sendo justamente a etnografia uma abordagem preciosa com o poder de descortinar aquilo que muitas vezes fica oculto nas análises de cunho mais generalistas.

Os estudos etnográficos do trabalho têm uma história nas ciências sociais que não podemos desenvolver aqui, mas que mostram aquém e além do atlântico a pertinência atual desse tipo de abordagem. Hoje, vemos que a sociologia do trabalho e outras áreas afins se encontram, de algum modo, encapsuladas em conceitos, com os quais se debatem diariamente, tais como os de flexibilização, terceirização, polivalência e precarização. Inúmeras pesquisas têm sido efetuadas e milhares de artigos têm sido escritos, nas últimas décadas, se utilizando dessas ferramentas conceituais, que se deve dizer não são descoladas da realidade empírica do trabalho. Contudo, não se tratando de descartá-las caberia indagar em que medida podemos ir além delas, e procurar novos achados sobre a realidade do trabalho em nossas sociedades, que não se resumam a ditar a reprodução particular de um contexto geral ou de uma tendência global, mas sim em verificar o 
quanto a singularidade do objeto empírico tende a nos ensinar sobre os processos reais que vivenciam os indivíduos. Talvez esse seja o nosso maior desafio nos marcos de uma sociologia do trabalho reconfigurada na atualidade.

Nesse sentido, sabíamos que ao lançar a proposta deste número precisaríamos estar abertos à diversidade de abordagens que poderiam emergir, desde as distintas e plurais realidades do mundo trabalho. Em nenhum momento, como organizadores, pretendemos nos colocar como autoridades burocráticas especializadas em julgar o caráter etnográfico dos artigos que receberíamos. Para tanto, procuramos visualizar nos artigos que compõem o dossiê, elementos que costumam estar presentes nas pesquisas etnográficas, mas sem a pretensão de construir uma espécie de "etnografômetro" que medisse quanto um artigo era ou não fruto de uma abordagem ou pesquisa etnográfica. Nesse sentido, estudos longos, espaços sociais configurados como comunidades, descrições rigorosas, observações detidas, reflexividade sociológica, valorização do empírico diante do teórico, resgate do ponto de vista dos trabalhadores são elementos que aparecem com diversidade de matizes, nos artigos do dossiê, como recursos etnográficos mais que como etnografias com títulos maiúsculos.

O dossiê é composto por dez artigos que foram organizados em três momentos analíticos. O primeiro momento parte de uma visão mais global sobre as potencialidades macrossociológicas da etnografia, seu lugar "teórico" (se é que cabe este termo), suas certezas e incertezas metodológicas e sua aterrisagem em um objeto tão importante ao trabalho (e talvez tão necessário, ainda hoje) como é o sindicalismo. Inicia com o artigo (capítulo de livro) intitulado "Procurando pelo Global" de Michael Burawoy, que foi traduzido para este dossiê. O sociólogo britânico começa por questionar a possiblidade de uma etnografia global, isto é, em que medida o estudo da vida cotidiana permite ir além das fronteiras nacionais. Afastando-se de uma visão extremamente localista da etnografia, Burawoy nos convida a ampliar nossos horizontes analiticos. Para tanto, atravessa tanto os debates 
sobre globalização, pós-modernidade e sociedade informacional como percorre as tradições interacionistas e etnográficas da sociologia e da antropologia.

$\mathrm{Na}$ sequência, o segundo artigo com o título "Etnografia, teoría fundamentada y frónesis: la relevancia del contexto" de Alexander Castletón (sociólogo uruguaio radicado no Canadá - Carleton University), propõe-se, a partir da problematização da noção de "frónesis", uma abertura orientada à complexidade e a ambiguidade da realidade social. A abertura, proposta pelo autor, afirma-se na sabedoria prática do pesquisador, a qual the fornece uma "compreensão útil" dos fenômenos sociais. Expondo algumas dimensões de uma etnografia situada em um contexto fabril, no Uruguai, Castletón enfatiza o lugar que ocupa a descrição minuciosa dos contextos em que se inscrevem as experiências laborais, bem como a importância de estruturar uma visão que ultrapasse a simples descrição. Tais características específicas, contribuem para a compreensão das complexas relações desiguais de poder que se estruturam no trabalho, nos dias atuais, assunto que precisa ser salientado como um aporte necessário, de acordo com as realidades laborais globais do século XXI.

$\mathrm{O}$ terceiro artigo, deste primeiro momento, consiste em um relato metodológico sobre uma experiência etnográfica no sul do Brasil, de Pedro Marchioro intitulado "Relatos sobre uma etnografia do trabalho no Polo Naval de Rio Grande: a possibilidade de uma experiência ética e estética no processo de construção dos objetos de pesquisa". A relação entre trabalhadores locais e de fora, em um grande empreendimento da indústria naval brasileira, na cidade de Rio Grande-RS, foi abordada pelo autor a partir da aproximação etnográfica. Seu relato demonstra como foram descortinadas essas relações, em que o rótulo de "baiano" para com os "estrangeiros" (brasileiros, mas não gaúchos) acabava por remeter para uma realidade local que havia sido desestabilizada por esse gigantesco empreendimento, no sul do Brasil, bem como para a experiência enriquecedora do pesquisador no campo. 
Fechando o primeiro momento do dossiê temos o artigo "El XIII Congreso del PIT CNT Wladimir Turiansky: una observación etnográfica" de Marcos Supervielle, Leonel Rivero e Leonardo Cosse (sociólogos uruguaios). Este artigo - quarto no dossiê - apresenta uma abordagem inovadora sobre os sindicatos no Uruguai, com uma etnografia das assembleias, seu máximo órgão coletivo. O congresso como instância em que se condensa um momento privilegiado para compreender a cultura sindical é colocado em perspectiva, desde as tensões teóricas que o trabalho etnográfico possibilita. Os autores chamam a atenção sobre a necessidade de elaborar "categorias de entendimento", que em um sentido "operacional" permitam aprofundar as observações, ao mesmo tempo em que se constituam em propulsores do sistema interpretativo. As categorias do entendimento que se colocam em discussão exigem ajustar-se aos sentidos emergentes, que no caso exposto no artigo, problematizam a relação entre o sentido do trabalho e as políticas de desenvolvimento, no contexto das relações entre atores sindicais e sistema politico. A categorização emergente pode ser entendida, neste quadro de análise, como uma aposta que ultrapassa os limites de sentido restritos a tal investigação situada, permitindo um olhar político mais amplo sobre os processos sindicais, na atualidade.

O segundo momento deste dossiê, reúne uma série de pesquisas etnográficas que contribuem para visibilizar as manifestações heterogêneas que assumem o trabalho e os trabalhadores, nos dias atuais. Assim, o artigo intitulado "Nocturnidad y Noctis: consideraciones para la etnografia de trabajo de producción de nocturnidad", do sociólogo mexicano Julio César Becerra Pozos - quinto artigo do dossiê -, aborda uma categoria de trabalhadores com certa "instabilidade relativamente estável", que abrange garçons e garçonetes de bares no México. A discussão em torno ao "trabalho não clássico", desde um olhar etnográfico, é o ponto de partida que se propõe o autor para problematizar experiências laborais que se expandem estatisticamente pelo planeta, com foco nos debates expostos em relação à "nocturnidad". Nesse sentido, a pesquisa abre as portas para 
repensar experiências ambivalentes, contraditórias e complexas que, para além de sua magnitude ou da possibilidade de generalização de suas características em termos de fenômenos sociais do trabalho, permite mostrar um mundo de sentidos que perpassa as experiências de milhões de trabalhadores em todo o planeta. Esses trabalhadores, por sua vez, não se "localizam" no vetor de "típicos" das identidades laborais, constituindo em muitas pesquisas o "lado oculto" (a dimensão menos explorada e compreendida) da precariedade, da falta de segurança ou da marginalidade do trabalho.

A seguir temos o artigo intitulado "Trabalho e produção associada ao turismo: tensões e rupturas no processo de construção da identidade de mulheres na comunidade rural Chã de Jardim" - sexto artigo do dossiê -, de Josilene Ribeiro de Oliveira, que analisa o trabalho de mulheres sitiantes na área do turismo na cidade de Areia, na Paraíba. A aproximação etnográfica realizada pela autora lhe permitiu verificar o alto protagonismo das mulheres no trabalho com turismo, junto com a percepção corrente deste último como sendo uma "ajuda", isto é, complementar. Contudo, essa experiência revela a busca de valorização e autonomia por parte das mulheres. A pesquisa, com traços etnográficos, permitiu identificar três dimensões relevantes do trabalho, como mediador de relações humanas, como valor moral e como dádiva.

Fecha o segundo momento do dossiê, o artigo de João Matheus Soares Miranda intitulado "Dimensões do mototrabalho em Pelotas-RS: experiências de (in)formalidade e precariedade" - sétimo artigo do dossiê. O autor pesquisou, através de uma metodologia aproximada à etnografia, os motoboys na cidade de Pelotas-RS. Utilizando-se de recursos etnográficos, Soares Miranda traz um olhar renovado para investigar temas tão caros da sociologia do trabalho, como a informalidade e a precariedade, através de uma categoria de trabalhadores relativamente nova, motoboys e mototaxistas. Ele observou como essa experiência de trabalho que costuma ser vista, não erradamente, como uma situação de intensa precariedade laboral, 
convive com um distanciamento subjetivo dos trabalhadores em relação ao trabalho formal e com proteção social.

O terceiro momento do dossiê é reservado a estudos com diferentes intensidades etnográficas, mas que têm em comum serem resultado de pesquisas com sujeitos que se encontram nas margens da sociedade, entre o trabalho legítimo e o não tão legítimo (catadores de material reciclável) entre o trabalho formal e informal, entre o trabalho e o desemprego. O primeiro artigo desse momento - oitavo artigo do dossiê - com o título "O trabalho e o movimento nas tramas urbanas: condição de mobilidade e recurso social de catadores de materiais recicláveis", de Ari Rocha da Silva, analisa os trabalhadores que coletam materiais recicláveis na cidade de Passo Fundo-RS. A pesquisa procura transcender os mundos desses trabalhadores como sendo determinados pela miserabilidade. O autor procura mostrar a complexidade dos "mundos vividos" por esses trabalhadores. Sua análise propõe compreender a vida desses indivíduos como sendo a de um trabalhador multifacetado, e não apenas como um catador de materiais recicláveis. A busca por exercer outras atividades aponta que, somente por meio de um exercício intelectual reducionista, as trajetórias desses trabalhadores podem ser interpretadas, simplesmente, com um trabalho exclusivo de coleta de materiais recicláveis.

A seguir temos o artigo intitulado "Discriminación, degradación y biologicismo: el tratamiento dado a los últimos peldaños de la clase trabajadora en Córdoba, Argentina” de Juan Manuel Zeballos - nono artigo do dossiê. Zeballos problematiza, para um caso de pesquisa realizada no contexto de bairros populares na cidade de Córdoba ("villas"), a relação entre condições materiais de existência e experiências de "viver de ocupações precárias" e em condições de sócio segregação habitacional urbana. $O$ artigo enfatiza as percepções vinculadas com as práticas discriminatórias, encontrando como traço a salientar que os sentidos envolvidos, entre outros, a expressões como, por exemplo, "negro de mierda", estão associados a processos de legitimação social da "miséria". 
Encerra o terceiro momento do dossiê - décimo e derradeiro artigo do conjunto do dossiê - intitulado "Onde moram os precarizados: a interlocução entre precarização do trabalho e estigma territorial", de Silvia Adriana Lima Corrêa. Este artigo dialoga, de algum modo, com o do autor anterior, pois ambos problematizam a estigmatização de setores de trabalhadores que se encontram nas margens da sociedade. Lima Corrêa, por sua vez, recorre a recursos etnográficos para descrever a vitalidade da categoria trabalho, em uma pequena comunidade, na zona sul da cidade de Manaus, no norte do Brasil. O trabalho aparece nessa comunidade como um elemento de distinção simbólica que separa trabalhadores formais e "desocupados". Classificação e desclassificação social de setores precários mostram um cenário em que o trabalho significa distinção quando se possui e estigmatização quando dele se carece. A autora ainda nos remete para outro achado, conjuntamente relevante. Em um contexto neoliberal, são os ocupados os que "produzem" os desocupados (para fazerem os trabalhos que eles não querem fazer), ao mesmo tempo em que desejam sua inexistência.

A maior marca do dossiê aqui apresentado é a de reunir artigos que são fruto de abordagens etnográficas, entendidas em um sentido amplo. Em alguns casos notamos abordagens mais propriamente etnográficas, e em outros, aproximações etnográficas ou pesquisas com traços etnográficos ou fazendo uso de recursos etnográficos. Esse olhar amplo nos permitiu trazer, para os leitores, artigos abordados em universos singulares e demarcados pela pluralidade de casos e objetos de estudo passiveis de serem analisados. A apresentação deste dossiê tem tido como pretensão principal mostrar que os estudos, sobre os "mundos" do trabalho, têm muito a ganhar quando recorrem às abordagens etnográficas; entre outros aspectos, para reinventar pressupostos teóricos, metodológicos e epistemológicos sobre as particularidades emergentes no conjunto das relações laborais (COSTA; ALAMADA, 2018). A interpretação sociológica dos "mundos" de trabalho, numa época global, precisará cada vez mais de estudos que se 
aproximem às abordagens etnográficas, no mínimo para escutar - como tentamos fazer aqui - o que nos dizem aqueles e aquelas que carregam esses mundos cotidianamente.

\section{REFERÊNCIAS BIBLIOGRÁFICAS:}

BURAWOY, Michael et al. Ethnography Unbound: Power and Resistance in the Modern Metropolis . University of California Press. Berkeley. Los Angeles. Oxford. 1991.

BURAWOY, Michael et al. Global Ethnography: Forces, Connections, and Imaginations in a Postmodern World. University of California Press. Berkeley. Los Angeles. London. 2000.

COSTA, Elizardo Scarpati; ALMADA, Pablo. "Mundo do trabalho e pluralidade epistemológica: uma contribuição para o estudo da precariedade". In: Sociologia: Revista da Faculdade de Letras da Universidade do Porto, Vol. XXXV, 2018, pp. 161-179.

GUBER, Rosana. La etnografia. método, campo y reflexividad. Buenos Aires: Siglo XXI, 2011. 